\title{
ENTREVISTA COM A PROFA DRA. VÂNIA MARIA RESENDE
}

Educadora, Doutora em Letras (Estudos Comparados de Literaturas de Língua Portuguesa pela USP), especialista em Literatura Brasileira e Literatura Infantil e Juvenil. Atua nas áreas de crítica literária e promoção da leitura, com cursos, oficinas, palestras. Nessas áreas tem alguns prêmios - concedidos pela UBE (SP), FNLIJ, MinC, UFSJ, Casa de Cultura Josué Montello, entre outras instituições -, colaborações com artigos, capítulos em livros e as publicações autorais: Literatura infantil e juvenil - vivências de leitura e expressão criadora; $O$ menino na literatura brasileira; Ziraldo e o livro para crianças e jovens: revelações poéticas sob o signo de Flicts.

Questões formuladas por José Hélder Pinheiro Alves (UFCG) e Raquel Beatriz J. Guimarães (PUCMG)

Entrevistadores: No final da década de 1970 e no decorrer das décadas seguintes você desenvolveu um trabalho que consideramos pioneiro no ensino de literatura, mais especificamente da literatura Infantil e Juvenil. Este trabalho - realizado na Universidade, em Secretarias de Educação Municipais, em assessoria a órgãos estaduais e escolas particulares - resultou em dois importantes livros. Gostaria que você falasse dessa trajetória. Destaque as influências recebidas, o diálogo com outros pesquisadores dentre outros aspectos que você considere relevante.

Quando me formei em 74 em Uberaba, como ocorria na maioria dos cursos de Letras do país, a Literatura Infantil não integrava o currículo como disciplina. No caso do meu curso, também não fazia parte de Metodologia e Prática de Ensino de Língua Portuguesa, nem compunha alguma unidade dentro dos conteúdos dos programas das Literaturas de Língua Portuguesa; quanto à Brasileira, esses programas consistiam em uma tomada panorâmica, digamos geral, dos períodos literários, e depois, aprofundamento particularizado nos gêneros Poesia e Romance. Na condição de aluna, em 74 assumi a abordagem panorâmica, como professora monitora, dando continuidade ao que se vinha fazendo anteriormente; porém, introduzi na programação um semestre de Literatura Infantil. Isso foi possível porque, seguindo a sugestão do Prof. Luiz Alberto de Miranda, de quem fui monitora, me inscrevi para um curso de Literatura Infantil, de umas 30 horas, ministrado em janeiro de 74 por Maria Antonieta Cunha, então professora na UFMG. Iniciei-me, assim, muito bem pela sensibilidade crítica de quem tinha visão da relevância desse universo literário, do qual eu não conhecia nada até então. Fui me apropriando da beleza e da riqueza de um corpo de obras diferenciado, que seria fonte e instrumento de formação de leitores, entendendo que, bem usado, poderia preencher os vazios existentes e corrigir inadequações. Nesta direção, revisões e posicionamentos caberiam às universidades, gerando mudanças em si mesmas e nos outros níveis de ensino. Encantada com a Literatura Infantil, nunca mais a separei da Literatura Brasileira, em todas as instâncias do meu trabalho, inclusive, na direção de pesquisa que escolhi quando fiz o doutorado, bem depois dos anos 70 .

Se a literatura infantil não era cogitada pelos cursos de Letras, em consequência também não entravam em cogitação questões como o quê fazer e como fazer, tratando-se de Literatura e Ensino Fundamental. A visão panorâmica a que me referi, de alguma forma, organizava certas diretivas, puramente diacrônicas, para o Ensino Médio (ficando fora disso orientações específicas para o Curso Normal). Sem se instrumentalizar, os profissionais saíam 
da universidade sem referência, e se sentiam desnorteados e angustiados. Uma luz vinha sendo acesa pela professora universitária de Literatura, Nelly Novaes Coelho, que foi precursora nas preocupações e apresentação de iniciativas metodológicas, esboçadas já em 1966 no seu livro $O$ ensino da literatura - sugestões metodológicas para o Curso Secundário e Normal. No decorrer do meu percurso profissional, tive o privilégio de me enriquecer em contatos e experiências com ela, e cheguei também a estreitar laços com Lúcia Pimentel Góes, que foi sua discípula; as duas sedimentaram um trabalho afinado na disciplina Literatura Infantil na USP. Absorvi da Lúcia (que produziu contribuições importantes com pesquisas, aulas, criações teóricas e literárias) análises pioneiras de cunho semiótico; ela foi minha orientadora no doutorado, defendido em 2004.

1980 foi marcante com a realização, pela Fundação Nacional do Livro Infantil e Juvenil e a Faculdade de Educação/ UFRJ, do I Encontro de Professores Universitários de Literatura Infantil e Juvenil, fomentando um pensamento reflexivo coletivo sobre a importância da disciplina nos cursos de Letras, Pedagogia, Biblioteconomia, Psicologia, e no Curso de Magistério. Daí resultou um documento encaminhado a diversas instituições universitárias, propondo a inclusão da Literatura Infantil. Os ANAIS produzidos pela FNLIJ registram 42 presenças, incluindo os observadores; dos 24 especialistas presentes, 20 apresentaram comunicações, que constam do documento, pondo em evidência caminhos $d a$ e para a Literatura Infantil. A baixa representação de professores universitários da disciplina no evento revelou o cenário da época; quanto à representação de professores do interior, ficou reduzida a minha presença e à apresentação da minha comunicação intitulada "Iniciação ao estudo da Literatura Infantil e Juvenil".

Cada geração, na sua época, cria entrelaçamentos, que têm a possibilidade de ser pessoal e socialmente frutíferos. A relação com pessoas certas, que são luz para outras, em hora e lugar certos, favorecem a percepção clara do presente e dos seus vazios e necessidades e do que deve ser feito, buscando, no conjunto, alterar a ordem das coisas. Destaquei, na minha trajetória, algumas referências e deixei de mencionar outras tantas fundamentais. Mas, em conclusão, quero dizer que sou grata pela oportunidade de influências e encontros valiosos que o meu tempo tem me proporcionado.

Entrevistadores: Quando você, na década de 1970, criou e ministrou a disciplina Literatura Infantil e Juvenil no curso de Letras da FISTA - Faculdades Integradas Santo Tomás de Aquino - em Uberaba, quais as dificuldades encontradas? Você tem acompanhado o alargamento dessa disciplina no Brasil? Como você vê o que está ocorrendo hoje?

Posso atribuir dificuldades apenas à condição incipiente e novata da disciplina, quando a inseri dentro do curso. Isso me exigiu como que uma defesa da sua validade, um cavar espaços, para que ganhasse terreno e adeptos. A receptividade e as adesões foram fáceis, tanto da parte da instituição universitária, quanto de determinados professores do curso. Inspireime, evidentemente, no curso que fiz com Maria Antonieta, o que me deu norte. Tive autonomia para empreender qualquer ação, que, decorrendo da proposição de uma nova abordagem pela Literatura Infantil e Juvenil, repercutisse em benefícios pedagógicos e culturais dentro e a partir do curso se Letras. Tudo o que provinha da disciplina, de novo, criativo e produtivo, foi profícuo, e gerador de uma boa relação com outras disciplinas, promovendo, também, o diálogo da academia com a comunidade e as escolas de Ensino Fundamental e Médio, por meio, sobretudo, de ações e projetos de extensão.

Não tenho como fazer uma avaliação objetiva do que ocorre hoje, o que demanda uma pesquisa objetiva, com coleta de dados concretos e precisos. Limitando-me ao que constato 
empiricamente, aqui e ali na realidade, há reflexos de mudanças significativas, sim, mas não tenho noção de amplitude e profundidade de uma evolução histórica, de proporção nacional. Principalmente dos anos 80 em diante, um novo pensamento sobre a Literatura Infantil, a recepção infantil, etc. têm sido disseminados; há produção científica de dissertações e teses, voltadas a ela com interesse, e ganham expansão considerável, o que representa passos de amadurecimento da Crítica. Passado o tempo de maior efervescência que ocupou espaços e profissionais (não apenas da área de Letras), são bem-vindas e necessárias análises que confiram o que realmente do que se concebeu de novo se sedimentou em transformações sistêmicas.

Não nos esqueçamos de que no plano acadêmico, e não raramente, há ainda preconceitos e rejeições que recaem sobre a Literatura Infantil, procedentes de posicionamentos anti-científicos, não fundados numa leitura ampla, isenta e honesta da produção literária, sobretudo contemporânea, para crianças e jovens.

Entrevistadores: Em sua militância na divulgação da literatura infantil e juvenil, um importante acontecimento foi a realização de concursos literários dirigidos a crianças e adolescentes. Como se deu a idealização desses concursos? Por que foram interrompidos? Que avaliação você faz deles, hoje?

Os concursos foram gerados com caráter de extensão na relação da disciplina Literatura Infantil e Juvenil com as escolas de Ensino Fundamental e Médio, promovendo inicialmente o incentivo à escrita criativa motivada pela relação com a leitura literária. Esse propósito se explicitou melhor, quando foram acompanhados a cada lançamento anual do documento Programa de Incentivo à Leitura e à Escrita Criativa, que foi redigido e impresso para agregar ao regulamento, trazendo orientações - algumas bases teóricas, recomendações e sugestões - às escolas do Estado de Minas Gerais. As bases desse Programa eram experimentadas em uma escola pública de Uberaba ao longo de um ano. No seu sétimo ano o projeto ficou abalado pela dificuldade de publicação do livro com textos e ilustrações de crianças e jovens. Logo em seguida, o curso de Letras entrou em crise, caminhando para suas últimas turmas. E assim o projeto teve seu fim.

A experiência foi válida, aconteceu de acordo com os recursos disponíveis no momento (os meus, de professora da disciplina, e dos dois espaços universitários que a assumiram institucionalmente); contribuiu para o envolvimento das escolas com a literatura infantil, cresceu e ganhou amadurecimento dentro mesmo do tempo em que se realizou, propondo-se como um programa abrangente de leitura e escrita para o ensino fundamental. $\mathrm{O}$ que eu faria sob o ponto de vista de hoje: ênfase ao funcionamento de oficinas de produção de textos criativos, propondo que os textos das crianças e dos jovens, enviados para a publicação coletiva, fossem fruto lentamente amadurecido nas suas experimentações diárias no espaço da escola; também proporia a realização de oficinas para os professores orientadores desse processo.

Entrevistadores: Em seu livro Literatura infantil \& Juvenil: vivências de leitura e expressão criadora, há reflexões teóricas, relatos de vivências e sugestões de atividade em sala de aula sobre os mais diversos gêneros literários e para todas as séries do ensino básico. Você tem uma avaliação da recepção e influência que essa obra teve e continua tendo? 
A editora Saraiva é bem estruturada em termos de divulgação e penetração em todo o território nacional, e isso facilita o acesso aos interessados. Sei que o livro tem cumprido um papel. Chegou bem, fez parte de alguns programas de salas de leitura, por exemplo, no Estado de Minas e na cidade de São Paulo, entre outros; integra também várias bibliografias, tanto de programas de cursos de Letras e Pedagogia, como de trabalhos científicos acadêmicos. Sobre as influências, a avaliação é um tanto imponderável - tudo vai sendo incorporado a longo prazo por quem se utilizou e se utiliza do livro, fugindo ao controle do autor todas as ressonâncias explícitas e sutis. Vez ou outra me alegro, quando chego a algum lugar e vejo citações extraídas dele, em murais, paredes de escola, em artigos, dissertações, etc.

\section{Entrevistadores: Você esteve ligada ao PROLER, no auge deste importante programa de leitura. Que avaliação faz dele no contexto nacional?}

Ao PROLER cabe o papel importante de ter desencadeado uma multiplicidade de focos de incentivo à leitura, congregando, em propósitos afins e ações promotoras de leitura, especialistas, escritores, ilustradores, educadores, bibliotecários, auxiliares de biblioteca, gestores, etc. Isso lhe imprime um perfil singular e inédito. Ele trouxe em si também o embrião para o traçado de uma política pública de leitura para o país, o que requer compromisso da sociedade como um todo, mas sobretudo a responsabilidade das esferas governamentais municipais, estaduais e federais. Mesmo sendo positivas iniciativas como esse Programa, que se define com importância histórica, a promoção da leitura no Brasil segue passos distantes de uma consolidação de acesso democrático e de qualidade aos bens culturais como o livro e a leitura literária. Para que se chegue a isso, o ato de ler tem que se definir e ser vivido como experiência contínua, não circunstancial; em tal condição é que a leitura flui na sociedade, na cultura e na educação como necessidade natural, cotidiana, espontânea e livre, não se confundindo com eventos, nem ficando na dependência deles, ou restrita ao incentivo do momento.

Entrevistadores: Você acompanhou outros projetos como Literatura em minha casa e, atualmente, o PNBE? Que contribuição estes programas trouxeram ou trazem para a formação de leitores no Brasil? Com relação a este último, tem acompanhado os acervos? Tem alguma avaliação sobre eles?

Participei em uma etapa do PNBE, como parecerista de determinados títulos do acervo escolhido pela FNLIJ; a convite da Fundação assumi a leitura crítica. Enquanto constituição de acervo e distribuição para escolas públicas de todas as localidades brasileiras, dos mais distantes pontos geográficos, é um Programa único, precioso e louvável, que vem fazendo história. Com relação ao que tive conhecimento, as diferentes etapas pautam em escolhas diversificadas e de qualidade. A seleção para o Ensino Médio, por exemplo, entre os títulos que vi, inclui obras completas, por sinal, de grandes autores, poetas, da Literatura Brasileira e Portuguesa, clássicos e modernos. Quanto à literatura infantil o projeto gráfico padronizado dos livros descaracterizou o projeto original das edições, e perdeu esteticamente.

O Programa atinge o objetivo de constituir e encaminhar os acervos para as escolas públicas, o que é feito como processo criterioso. Nem sempre, porém, as escolas os utilizam bem, às vezes, até os deixam guardados sem uso. Existem falhas metodológicas, associadas ao mau funcionamento ou não funcionamento da promoção da leitura em vários espaços escolares. A experiência da etapa "Literatura em minha casa", por exemplo, esteve longe de atingir os objetivos a contento, porque a escola não fez a mediação devida. Tenho 
testemunhado também experiências positivas, encontrando por aí afora muitos educadores que têm acesso a obras e autores contemporâneos, graças ao contato com os acervos distribuídos pelo PNBE. Na verdade, dois pontos são fundamentais para que a formação de leitores deslanche com sucesso: bons acervos e promotores de leitura competentes, que os utilizem bem.

\section{Entrevistadores: Que análise você faz do modo como a literatura aparece nos Parâmetros curriculares nacionais, especialmente as OCEM-2006?}

Não há dúvida de que são documentos bem fundamentados teoricamente, visando uma inter-relação entre as áreas diretamente implicadas entre si e com o ensino da Língua, como Linguística, Linguagem, Semiótica, Comunicação, etc. Se bem assimilados e aplicados com propriedade, há enriquecimento no ensino da Língua, devido à abertura aos múltiplos letramentos e à compreensão da complexidade dos vários sujeitos (e das várias situações que um mesmo sujeito possa experimentar, linguisticamente falando), determinada pela diversidade de condições históricas, psicossociais, contextuais. A perspectiva semiótica que perpassa as propostas é positiva, visando o máximo e melhor uso possível da Língua, na expressão e recepção de uma gama ampla de gêneros, códigos e meios de comunicação. Mesmo reconhecendo avanços oriundos dessa visão dos múltiplos letramentos, mantenho a convicção do poder diferenciado do gênero "literatura" e da relevância da leitura literária para a educação humanista, a formação complexa da consciência, a capacidade de um pensar profundo, reflexivo, com burilamento criativo e sensível. Não percebi ênfase quanto a isso nos documentos, mas, sim, colocada sobre a importância de duas vertentes - da multiplicidade e da complementaridade de gêneros textuais, todos com igual valor no atendimento à competência na comunicação linguística; as duas vertentes são apontadas como aptas a munirem o sujeito das melhores condições para se colocar no mundo em todas as situações de uso da Língua.

\section{Entrevistadores: Durante alguns anos você criou e manteve uma livraria especializada em Literatura infantil e juvenil que tinha um propósito educativo. Fale um pouco desta experiência. $O$ que a levou a desistir do projeto?}

Foi uma grande experiência, que me permitiu penetrar socialmente, de maneira mais ágil e imediata, em termos da democratização do acesso ao livro e à leitura, atingindo um público diversificado. Na Livraria vi acontecer também o melhor entrosamento dos planos social, cultural, pedagógico, com resultados incríveis. Foi um sonho projetado que se tornou realidade, vivida de maneira vital. Foi um espaço de articulações inéditas, fluidas, ousadas, em que realizei com total liberdade e autonomia as minhas convicções na promoção da leitura num contex to de muita ação criativa.

Assumi o sonho com todos os riscos e encargos. O que projetei foi concretizado de maneira ideal, sem expectativa de lucros financeiros, mesmo porque, para mantê-lo, eu trabalhava paralelamente em outras frentes que me sustentassem, e o que poderia ser ganho material era aplicado na realização de muitos projetos de leitura e ação cultural e educativa. Não teria como esse sonho ser repassado a meros comerciantes, porque ele era parte do meu contexto, da minha história, duraria mesmo enquanto eu pudesse nutri-lo com a minha vitalidade, resguardando-lhe o perfil singular. A Livraria enquanto espaço comercial não entrou em crise; eu, sim, tive necessidade de renovar as estratégias e energias, realojando o sonho da leitura e da literatura em novas situações. 
Entrevistadores: Qual seria para você o objetivo principal do trabalho com o texto literário na escola? Você considera que esse objetivo vem sendo alcançado? Há alguma diferença entre o que se fazia há 30 anos atrás e o que se faz hoje?

O lugar que a leitura literária ocupa na esfera pedagógica da escola carregará sempre, para mais ou para menos, uma dimensão paradoxal, onde é impossível estarem de pleno acordo o consentimento ao prazer estético com gratuidade e a estrutura pedagógica (arranjo, funcionamento e avaliação dos conteúdos sistematizados). É procedente se conceber mesmo como "trabalho" o que se empreende nesse espaço, pretendendo inserir o leitor no mundo da literatura, onde promover a leitura e ler não são atos descomprometidos, a menos que sejam limitados a passatempo, ficando a escola, nesse caso, omissa na função de educar para a recepção participativa no contato com obras/autores nacionais e estrangeiros. A educação literária tem superado fases. Antes dos 30 anos mencionados na questão existiam ainda professores focados na informação biográfica, histórica (quanto à época do texto e do autor), localização de períodos literários; o texto não era o centro, ou não era visto do ponto de vista de interpretação literária, servindo até mesmo para exercício de análise sintática. Uma visão dinâmica, interacionista - que compreende o leitor em diálogo com o texto artístico, sem o que a literatura não cumpre a sua natureza plena de virtualidades - faria o ensino na área dar novos passos. Há que se observar que dessa nova visão, focada no texto e na relação do leitor com ele, surjam também tendências mal elaboradas, adotando o impressionismo ou a superinterpretação, valendo tudo o que a imaginação do leitor quiser, ou outras ainda que concebam o prazer pelo prazer, desconsiderando que, desde que haja a participação do leitor, mesmo sendo lúdica a fruição do texto, a leitura demanda atenção, envolvimento e empenho subjetivo.

Transitar pela natureza artística do texto literário a partir da permissão ao prazer estético é condição imprescindível. Não há como refreá-lo, em favor da função educativa, que pretenda seguir vias puramente racionais, sem que o leitor interaja, envolvendo-se subjetivamente. Acredito que se aquilata qualitativamente o valor da leitura literária para o leitor, quando a obra o toca na sua condição humana, revolvendo a sua realidade e a sua visão do mundo, transformando-o a partir de algum ponto (de um desejo, uma memória, uma emoção, uma ideia, um propósito...), e pode ser que ele nem tenha percepção consciente disso, embora já não seja o mesmo depois de uma boa relação com o texto.

Ainda prevalece, infelizmente, o pragmatismo na utilização do texto literário, servindo a puros pretextos, não reconhecido e descoberto na sua riqueza, beleza e complexidade, negadas as vias de interação subjetiva profunda e livre.

Entrevistadores: À parte seu importante trabalho na luta por um ensino de literatura que tivesse como eixo o texto literário, você teve uma importante produção na área didática e de crítica literária. Gostaria que falasse um pouco desta experiência. Penso, por exemplo, no importante ensaio sobre $O$ menino na literatura brasileira e seu mais recente ensaio sobre a obra de Ziraldo (Ziraldo e o livro para crianças e jovens no Brasil).

Sinto-me intimamente compensada, quando escrevo ensaios, isto é, críticas de maior extensão. Isso por dois motivos: estabeleço estreito diálogo com a palavra literária, que é fascinante, e ponho-me de corpo inteiro numa elaboração intertextual, conciliando pensamento reflexivo, sensibilidade e imaginação. Tenho estudos não publicados sobre alguns autores como Machado de Assis, Lima Barreto, Otto Lara Resende, que produzi motivada pelo prazer de escrever e às vezes de participar de algum concurso literário, como ocorreu 
com análises sobre os dois últimos autores, pelos quais recebi prêmio na área de ensaio, respectivamente da UBE (SP) em 80, e da Universidade Federal de São João Del Rey em 2007.

O menino na literatura brasileira é a obra que me deu maior realização em termos existenciais, estéticos e profissionais, pelo caráter do tema desenvolvido e por terem sido analisadas lado a lado no conjunto das obras a Literatura Brasileira, habitualmente chamada de adulta, e a Infantil e Juvenil. Foi também o estudo mais exaustivo, que me envolveu em doze anos de pesquisa e redação. Ziraldo e o livro para crianças e jovens no Brasil Revelações poéticas sob o signo de Flicts foi outra elaboração longa, minha tese de doutorado adaptada para publicação; fruto de estudos comparados, seguiu também a linha de aproximação e inter-relação, em que a literatura para crianças e jovens segue par a par com a literatura para adultos, livre de riscos de uma crítica que a exclui e da aplicação de critérios distintivos que reconhecem superioridade estética na segunda.

\section{Entrevistadores: Fique à vontade para falar de qualquer questão que julgar pertinente.}

Quero expressar meu orgulho por estar sendo entrevistada por você, Hélder, contando com a parceria da Raquel Guimarães. Vocês foram dois grandes alunos e são profissionais dedicados, fiéis ao amor pela literatura, no que nos tornamos cúmplices. Tenho admiração aos dois, e você, particularmente, louvo pela contribuição dada, com garra, lucidez e sensibilidade, especialmente à área da Literatura Infantil e Juvenil, num raio de abrangência que vai da Universidade Federal de Campina Grande ao entorno nordestino. Foi com emoção e prazer que voltei a tantos momentos da minha memória nessa nossa conversa. Muito obrigada por isso! 